\title{
Trust to Go Green:
}

\section{An exploration of consumer intentions for eco-friendly}

\section{convenience food}

\begin{abstract}
Interest in food products with eco-friendly characteristics and certifications has grown in recent decades. Consumers are also increasingly demanding ready-to-eat products, especially in urban environs, where modern lifestyles tend to limit their available time. Understanding the proenvironmental behaviour of convenience food consumers is particularly challenging because there is often a contradiction between eco-friendly behavioural intent and time constraints imposed by modern lifestyles in large cities. It is not clear to what extent information labels on such products are trusted by consumers and considered when making food choices. This study aims at contributing to the debate investigating the determinants influencing consumer purchase intention, focusing on minimally processed vegetables labelled with integrated-pest-management standards. More specifically, the analysis investigates the role consumer trust plays in consumer intention to buy such products. The conceptual framework builds on and extends the theory of planned behaviour. The analyses are based on face-to-face interviews in a large European city (Milan, Italy). Data were analysed by means of structural equation modelling. Results confirm the important role of consumer trust, which positively affects attitudes towards the purchase of convenience food with
\end{abstract}


eco-friendly attributes, and negatively affects consumer concerns around agricultural practices in relation to environmental and health impacts.

Keywords: consumer trust, convenience food, eco-friendly attributes, theory of planned behaviour.

JEL classification: D12, Q01; Q13, Q18.

\section{Introduction}

Interest in food products with eco-friendly characteristics and certifications has grown in recent decades in industrialised countries (Bougherara and Combris, 2009; Falguera et al., 2012; Nuttavuthisit and Thøgersen, 2017). So-called 'green' products like organic, pesticide free products, or food produced following integrated-pest-management practices, are perceived by most consumers to be low-processed, naturally grown, and healthier than conventional food products Goetzke et al., 2014; Hemmerling et al., 2016; Lee and Yun, 2015). Consumers are also increasingly demanding ready-to-eat products. In particular, in urban environs, modern lifestyles tend to limit the time availability of consumers (Botonaki and Mattas, 2010; Brunner et al., 2010). Thus, convenience food includes 'time saving' services in addition to the good itself, meaning that it is easier and quicker to prepare. Such products are, however, often criticised for not being environmentally sustainable for their technological production (Olsen, 2012).

In response to these contrasting consumer demands, food firms have begun to introduce convenience food with eco-friendly characteristics. In many food categories, including fresh, preserved, or frozen food, products that combine 
convenience and (some) eco-friendly attributes are becoming more widespread (Meredith and Willer, 2016). An increase in the eco-friendly voluntary standards adopted by food firms has also become noticeable (Del Giudice, 2018). For some attributes, firms are able to follow specific public standards (for example, for organic produce); for others, they refer mainly to private ones (for example, integrated pest management, where there is no unified and commonly agreed on standard defining what is and what is not integrated agriculture) (Banterle and Stranieri, 2013).

Understanding the pro-environmental behaviour of convenience food consumers is particularly challenging because there is often a contradiction between ecofriendly behavioural intent and time constraints imposed by lifestyles in large cities. Moreover, the loss of connection with nature that often arises in urban areas makes it even more difficult for consumers to access sustainable options (Schösler et al., 2013). Indeed, there is the need to find organizational or market solutions able to accomplish both time-saving and eco-friendly consumer needs. Previous research has explored extensively the role of consumer cognitive variables on consumer intention to engage in pro-environmental behaviour in relation to food choices. Specifically, consumer attitudes towards eco-friendly food products (Grunert et al., 2014; Honkanen et al., 2006; Lee and Yun, 2015) and consumer perceived availability of food with environmentally-friendly characteristics (Yadav and Pathak, 2016; Zhou et al., 2013) were found to be important predictors. Moreover, food-related literature has highlighted that consumer intention to buy eco-friendly products is influenced also by other variables such as food shopping habits (Menozzi et al., 2015) and consumer environmental and health concerns (Suki, 2016; Wee et al., 2014) . 
Trust has also been recognized as an important factor to explain food behaviour because it can represent a 'shortcut' to tackle the overwhelming amount of information that needs to be considered by consumers while shopping (Hobbs and Goddard, 2015). Indeed, in particular for food choices, heuristics are an important part of consumer decision-making processes (Chalamon and Nabec, 2016; Schulte-Mecklenbeck et al., 2013). Moreover, trust is particularly interesting in the specific case analysed in this study because the two product characteristics considered ('convenient' and with an 'eco-friendly' quality attribute) convey contrasting perceptions of the potential risks and benefits associated with buying the product. Convenience food is often perceived negatively by consumers because of its lack of 'naturalness' due to its processing (Jackson and Viehoff, 2016). Indeed, Evans et al. (2010) argued that food processing or manipulation leads to a decrease in the perceived natural content of the product, and Abouab and Gomez (2015) stressed that handmade food production is considered more natural than technology-embedded products. The lack of naturalness associated with convenience food is perceived to negatively affect the environment and human health (Asioli et al., 2017; Román et al., 2017). On the other hand, eco-friendly products evoke a higher naturalness and greater benefits associated with healthiness and taste (Agovino et al., 2017; Michaelidou and Hassan, 2008; Mondelaers et al., 2009). As trust has been found to be a factor influencing perceived risks and benefits associated with products (Prati et al., 2012; Siegrist et al., 2007), we believe that trust can be a means to guide consumer choice under such ambiguity.

While the determinants for either convenience or eco-friendly products have been largely explored (for a review, see Pearson et al. (2011) and Brunner et al. (2010)), the variables affecting consumer intention to buy convenience food with 
eco-friendly characteristics is still under investigated (Sillani and Nassivera, 2015). Moreover, to the best of our knowledge, there is no investigation on the role of trust in consumer intention to buy convenience food with eco-friendly characteristics.

The present study aims at analysing the determinants of the purchase intention for such products that combine both types of quality attributes (i.e., that are convenient - thus quick and easy to prepare - and have eco-friendly features that is, they have a lower environmental impact on at least one aspect, like water use, pesticide use, energy or carbon intensity, and so on). More specifically, the study concentrates on the case of minimally processed (MP) vegetables produced with integrated pest management (IPM) practices, namely, fresh vegetables processed to be ready to eat, and whose agricultural production relates to practices that reduce the use of chemicals compared to regular production processes. MP vegetables are a healthy convenience food that falls in the categories of convenience food proposed by Geeroms et al. (2008) and Brunner et al. (2010). Minimally processed fruit and vegetables represent an interesting market because even with their limited market share, the demand for such products is growing at a very fast and steady pace (Baselice et al., 2017; Nassivera and Sillani, 2017; Stranieri and Baldi, 2017; van Rijswick, 2010). The focus of the study is on vegetables as they constitute by far the larger part of the volume of such products (about 90\% according to Rabobank data (van Rijswick, 2011)).

Taking into account the above mentioned food products, the paper explores the following research questions. 
RQ1. Can the variables affecting consumer pro-environmental behaviour be used to explain consumer intention to buy convenience food with eco-friendly characteristics?

RQ2. Does consumer trust affect consumer intention to buy convenience food with eco-friendly characteristics?

The present analysis addresses the above-mentioned issues and it specifically investigates: if trust influences the intention to buy convenience food with ecofriendly characteristics, testing its relevance in an integrated behavioural framework.

The conceptual framework of the research - discussed in Section 2 - is based on the theory of planned behaviour (TPB) (Ajzen, 1985), which gives insights on the psychological determinants of behaviour that are useful for the economic analysis of consumer behaviour (Steiner et al., 2017). The study analyses the role of trust as a background factor in an extended TPB framework, which considers different variables predicting behavioural intention. To reach the aims of the study, a structural equation model (SEM) is applied to the data collected via a survey of food shoppers in a large European urban area, namely, Milan, Italy (details are reported in Section 3).

Within this context, the research questions of this study find strong support in the stream of literature that shows the significant contribution of trust to the intention to buy eco-friendly or technology-related products. Its contribution to the stream relates to investigating how trust influences consumer behavioural intentions in the case of the simultaneous presence of contrasting perceptions relating to product quality attributes. The understanding of the determinants leading consumers to buy such products is also crucial for an effective quality differentiation strategy by firms and for policy interventions aimed at 
encouraging and promoting sustainable practices in compliance with modern life styles, where choices are made under time pressure; specifically, focusing on consumers for whom pro-environmental behaviour is not the main priority while shopping (Aschemann-Witzel et al., 2013).

\section{Conceptual framework}

The conceptual framework starts from the TPB (Ajzen, 1985), which extends from the theory of reasoned action (Ajzen and Fishbein, 1980). Such a psychological-related framework allows us to integrate existing economic approaches for the analysis of consumer behaviour, which have been recognized to have limitations in the interpretation of the behaviour determinants (Johe and Bhullar, 2016; Vermeir and Verbeke, 2008; Yadav and Pathak, 2017). The TPB model was integrated by considering food-related literature. The resulting conceptual framework is presented in Figure 1. The hypothesized associations among the variables, indicated in the figure by means of arrows, are discussed below.

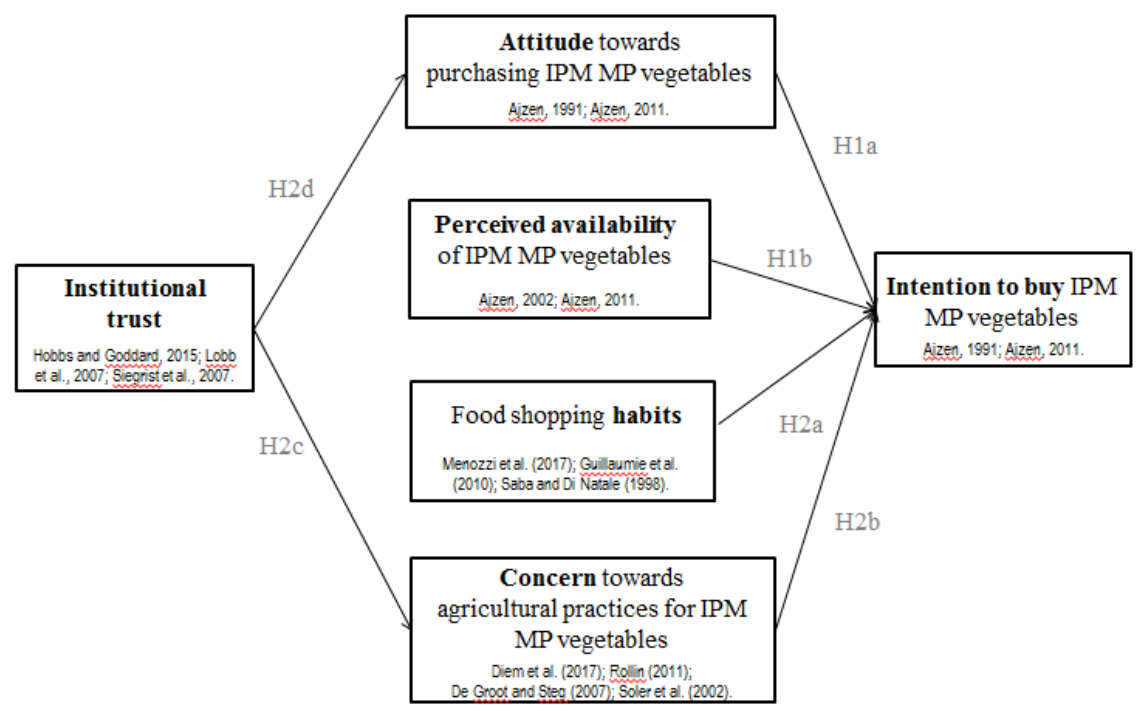

Fig. 1. Conceptual model

2.1 The TPB theory 
The TPB analyses the antecedents of specific human behaviours, evaluating the role of intention to perform the behaviour and its determinants. According to the theory, intention to perform a behaviour is influenced by: the evaluation of the possible consequences of performing that behaviour; the expectations of reference individuals; and the potential catalysts or impediments to that behaviour. In Ajzen's model, these beliefs form attitudes towards the behaviour, perceived behavioural control, and subjective norms, respectively.

Attitudes relate to consumer evaluation of the effects of having the behaviour. The more positive consumers feel about buying a certain product, the higher the probability is they will purchase such a product (Honkanen et al., 2006). On the basis of Ajzen's theory the research hypothesizes:

H1a: The more positive the consumer attitude is towards IPM MP vegetables, the higher the intention to buy them.

Perceived behavioural control refers to individual perception of one's own ability to perform the behaviour. It relates to the perceived ease or difficulty of implementing the behaviour. Such consumer perception can depend both on individual features (like the difficulty in performing the behaviour because it is too costly in terms of money, time, physical effort, etc.) or external circumstances (like the availability in supermarkets, the accessibility of certain information, etc.).

Product availability was found to significantly affect the decision to purchase eco-friendly food (Aertsens et al., 2009). Several studies have highlighted that the lack of product availability is one of the deterrents of choosing eco-friendly products, like organic food, and it contributes to the so-called 'attitudebehaviour gap’ for green consumers (Aschemann-Witzel and Niebuhr Aagaard, 
2014). Sillani and Nassivera (2015) also highlight that the perceived availability of eco-friendly food products is among the significant factors that can explain pro-environmental behaviour for MP vegetables. On the basis of Ajzen’s theory, the research hypothesizes:

H1b: The higher the consumer perceived availability is of IPM MP vegetables, the higher the intention to buy them.

The variables related to subjective norms measure consumer perceived social pressure to comply with the wishes of others (Ajzen, 1991). The aim is to evaluate consumer beliefs about what other people think they should do with regards to a specific behaviour and the relevance attributed to these. Literature on pro-environmental behaviour supports the idea that subjective norms can play an important role because of the social pressure exerted towards eco-friendly behaviour (De Leeuw et al., 2015). However, in this analysis, this determinant was not taken into consideration due to the debate still open in the literature ${ }^{1}$. In general, the authors acknowledge that social norms may have a significant effect on consumer behaviour, although in this particular study this effect should be weak as there is no strong social recognition related to IPM products. Moreover,

${ }^{1}$ First, there is, at the moment, little agreement on the precise formulation of the role of subjective norms within the TPB. Some authors state that this determinant has to be considered as an independent variable influencing behavioural intention (Harland et al., 1999; Smith et al., 2008), whereas other authors incorporate subjective norms as an indirect activator of attitudes (Kaiser et al., 2005). Second, the effectiveness of subjective norms to explain consumer behaviour is still highly uncertain and debated in the literature (Armitage and Conner, 2001). Indeed, different studies exclude subjective norms in their analysis for a number of reasons (Godin and Kok, 1996). Many authors have highlighted that the correlation between subjective norms and intention is weaker than the relationships of attitude and perceived behavioural control with buying intention (Sparks et al., 1995; Van der Putte, 1991). Other authors have argued that the weakness of subjective norms in predicting consumer buying intention relates to the fact that there are only a few individuals whose actions are merely influenced by social pressure (DeBono and Snyder, 1995; Trafimow and Finlay, 1996). Many other studies specify that moral norms are more influential than subjective norms for the individual intention to perform a behaviour (Godin et al., 2005; Sheeran et al., 1999). Third, several food-related studies do not consider this variable or ascribe it as a poor predictor (Blanchard et al., 2009; Chen, 2016; de Bruijn, 2010; Honkanen et al., 2005). 
compared to other behaviours, choices related to process attributes of food products - that are credence in nature - are not very visible to others. Thus, the social pressure related to such choices is very limited and should not affect the intention to buy IPM MP vegetables significantly.

The reason to adopt this framework is to try to, at least partially, overcome the limits of economic models based on the idea of individual choices driven only by self-interest, which do not work well in explaining consumer behaviour towards eco-friendly products (Turaga et al., 2010; Vermeir and Verbeke, 2006). The assumption being that purely self-interested consumers would not consider pro-environmental behaviour if this required increased costs or personal inconvenience (Johe and Bhullar, 2016).

\subsection{Trust and other determinants of food behaviour}

The TPB has been used as a framework of analysis when studying food-related behaviour (Arvola et al., 2008; Menozzi et al., 2017b) and also proenvironmental behaviour in different research fields in general (Bamberg, 2003; Chen, 2016). Focusing on food consumer behavioural models, different authors have stressed the need for additional variables to strengthen the explanatory efficacy of the theory (Lobb et al., 2007; Menozzi et al., 2015; Steg and Vlek, 2009; Stranieri et al., 2017). More specifically, food shopping habits, agricultural practice concerns, and consumer trust have been found to affect consumer intention to pursue an eco-friendly food choice (Govindasamy et al., 2001; Grankvist and Biel, 2001; Hobbs and Goddard, 2015; Menozzi et al., 2017a).

Food shopping habits relate to automatic actions that consumers conduct all the time during product procurement (Saba and Di Natale, 1998). Among these, consumer search for product label information is found to be positively related 
to the intention to buy food products, including fruit and vegetables (Guillaumie et al., 2010; Menozzi and Mora, 2012). Labelled information, which has been found to affect consumer intention to buy food products includes: the origin of product (Scarpa and Del Giudice, 2004), organic and sustainability labels (Bond et al., 2008; Van Loo et al., 2014), the shelf life date of food (Ragaert et al., 2004), and nutritional and health-related labelled information (Lyly et al., 2007). Following the above arguments, the research hypothesizes:

H2a: The higher the probability is to look for labelled information (food shopping habits), the higher the intention to buy IPM MP vegetables.

Consumer agricultural practices concern, namely, the perceived risks associated with agricultural practice, is found to affect consumer intention to buy ecofriendly products like organic produce (De Groot and Steg, 2007; Soler et al., 2002). More specifically, Tarkiainen and Sundqvist (2005) confirm that organic products can be viewed as an ethical choice promoted by environmental concern. Wee et al. (2014), Shafie and Rennie (2012), and Diem et al. (2017) highlighted that consumer health and environmental concerns positively affect the intention to buy organic products. On the other hand, literature on technology-embedded products, like convenience food, mostly highlights a negative relationship between consumer risk perception and the intention to buy such products (Rollin et al., 2011). On the basis of existing literature, a possible association between consumer concern and purchasing intention of IPM MP vegetables is recognised, even if the sign is not clear given that IPM products are more eco-friendly than conventional products but less than organic ones. Thus, the research hypothesizes: 
H2b: Consumer concern towards agricultural practices significantly affects consumer intention to buy IPM MP vegetables.

Finally, trust has been recognized as an important predictor of consumer beliefs and of consumer behaviour (Volland, 2017). Hobbs and Goddard (2015) stressed that most economic literature refers to generalized trust, namely, trust in others. However, institutional trust - namely, trust in institutions like governments and firms - has begun to be investigated by different authors as an important driver of consumer behaviour because it is considered a sort of heuristic, which influences consumer intention to buy products in the case of a lack of knowledge or time constraints.

Existing literature highlights how institutional trust may influence both consumer risk perception and attitudes. With regard to consumer risk perception, Lobb et al. (2007) found a negative relationship between trust in certain supply chain stakeholders and consumer risk perceptions towards chicken. In addition, Tonsor et al. (2009) confirmed that trust negatively affects risk perceptions of consumers in different countries. The same association was found for the effect of trust on perceived risks and benefits associated with eco-friendly products and technology-embedded products (Saba and Messina, 2003; Siegrist et al., 2007; Wee et al., 2014). Thus, the research hypothesizes:

H2c: The higher the institutional trust, the lower the perceived risks related to agricultural practices for IPM MP vegetables.

With regard to the relation between trust and consumer attitude, a number of studies have shown that the higher the consumer trust, the higher the probability to develop a positive attitude and, thus, to choose products with eco-friendly 
characteristics (Govindasamy et al., 2001; Grebitus et al., 2015; Pugliese et al., 2013).

Existing literature also highlights that there is a positive association between the level of trust and consumer preferences towards technology-embedded food like convenience food (Botonaki and Mattas, 2010; Bruhn, 2007; Rollin et al., 2011). McComas et al. (2014) discussed the importance of consumer perceived fairness of policy makers for the development of a positive attitude towards GMO products. In addition, Siegrist et al. (2008) showed that trust in the food industry was an important determinant to explain consumer attitudes towards food produced with the use of nanotechnology.

At the same time, current knowledge on the effects of trust on attitudes for processed food indicates that consumers with low levels of trust towards technology-embedded products prefer unprocessed and naturally-grown products (Çabuk et al., 2014; Magkos et al., 2006). Some eco-friendly attributes of food products, like being organic, or food from integrated-pest-management practices, indicate that they are 'naturally grown', therefore, of interest to consumers with low levels of trust due to technological scepticism (Pino et al., 2012; Storstad and Bjørkhaug, 2003). Thus, when these are attributed to convenience food, like MP vegetables, this can create ambiguity in interpreting previous literature insights about how trust should influence consumer attitudes towards such products. Indeed, eco-friendly convenience food is, at the same time, at least partially 'green' and processed. This leads to the following hypothesis:

H2d: Institutional trust significantly affects consumer attitude towards IPM MP vegetables. 


\section{Methodology}

\subsection{Data collection}

The study was comprised of a sample of 550 consumers in charge of their household food shopping. Consumers were selected randomly in front of supermarkets. However, only consumers that declared to be responsible for their household food shopping and to have purchased at least once MP vegetables were interviewed. Interviews took place at nine supermarkets in the Milan area, in the northern part of Italy, one in each of the nine different boroughs that divide Milan, to try to intercept consumers with different socio-economic demographics. Retail stores were listed according to their borough and selected randomly from the nine boroughs sub-lists (Dixon and Leach, 1977). For the same reason, consumers were interviewed at different times of the day (morning, lunch-time, afternoon, evening). Interviews were face-to-face and followed a set of predefined questions. Details on the resulting sample can be found in Table 1. The choice of the interview setting, namely, at supermarkets, relates to the aim of capturing consumers in a food-shopping frame of mind, to try to reduce biases in responses. Indeed, this should increase consumer ability to remember the difficulties faced when food shopping among many products with various types of attributes at different levels, and having to respond to budget constraints and household preferences.

\subsection{Construction of the variables}

The questions of the interviews were close-ended and based on a five-point Likert scale. The interview questions were constructed following the indications of the TPB and on the basis of the results of previous literature on food choices. 
Questions were pretested on a small sample of consumers, whose responses were not included in the dataset used for the analyses.

The structure of the questionnaire followed closely the conceptual framework discussed in Section 2. Following the TPB approach, each construct was investigated using multiple-item measures, namely, by including different questions to evaluate each latent variable. This should reduce the vulnerability of the data to measurement error and misinterpretation, and also allow to cover a broader range of meanings of the construct (Diamantopoulos et al., 2012).

More specifically, the questionnaire included a section analysing the intention to buy MP vegetables that are IPM, MP vegetables that are produced with a reduced amount of pesticides compared to ordinary products, and MP vegetables coming from agricultural practices with a reduced use of chemicals (variables $\left.\mathrm{INT}_{1}-\mathrm{INT}_{3}\right)$.

\begin{tabular}{|c|c|c|c|}
\hline Variable name & Scale & Variable descrption & Variable distribution \\
\hline \multirow[t]{3}{*}{ Gender } & dummy $0-1$ & & \\
\hline & 0 & male & $48 \%$ \\
\hline & 1 & female & $52 \%$ \\
\hline \multirow[t]{6}{*}{ Age } & scale $1-5$ & & \\
\hline & 1 & $18-24$ & $10 \%$ \\
\hline & 2 & $25-34$ & $16 \%$ \\
\hline & 3 & $35-44$ & $23 \%$ \\
\hline & 4 & $45-54$ & $22 \%$ \\
\hline & 5 & $>55$ & $29 \%$ \\
\hline \multirow[t]{6}{*}{ Education } & scale $1-5$ & & \\
\hline & 1 & primary school & $2 \%$ \\
\hline & 2 & secondary school & $16 \%$ \\
\hline & 3 & higher education & $45 \%$ \\
\hline & 4 & university degree & $29 \%$ \\
\hline & 5 & post degree & $8 \%$ \\
\hline \multirow[t]{6}{*}{ Income } & scale $1-5$ & & \\
\hline & 1 & very difficult to balance income and expenses & $9 \%$ \\
\hline & 2 & difficult to balance income and expenses & $22 \%$ \\
\hline & 3 & just enough income to balance expenses & $41 \%$ \\
\hline & 4 & easy to balance income and expenses & $21 \%$ \\
\hline & 5 & very easy to balance income and expenses & $7 \%$ \\
\hline \multirow[t]{6}{*}{$\begin{array}{l}\text { Frequency of purchase } \\
\text { of MP vegetables }\end{array}$} & scale $1-5$ & & \\
\hline & 1 & less than once a week & $28 \%$ \\
\hline & 2 & once a week & $18 \%$ \\
\hline & 3 & twice a week & $20 \%$ \\
\hline & 4 & three time per week & $14 \%$ \\
\hline & 5 & more than three times per week & $20 \%$ \\
\hline
\end{tabular}




\section{Table 1 - Sample description}

Furthermore, the study investigated the respondent's outcome evaluation of buying IPM MP vegetables, as an indicator of his/her attitude towards such products. The items referred to pest control, production costs of IPM production, use of pesticides, use of petrol, air emissions, and health impacts on farmers and local community (variables $\mathrm{ATT}_{1}-\mathrm{ATT}_{6}$ ).

The questionnaire also included questions related to consumer perceived behaviour control, namely his/her perceived ability to actually perform the behaviour, focusing on the accessibility of IPM MP vegetables on the basis of their availability in supermarkets, their price, their positioning, and the availability of price reductions (variables $\mathrm{PBC}_{1}-\mathrm{PBC}_{4}$ ).

Following the conceptual framework, the interviews focused also on additional factors with respect to the TPB. Indeed, a set of questions on consumer trust related to food production was included. More specifically, respondents were asked about their level of trust for: firms operating in the vegetable supply chain; food processor brands producing IPM MP vegetables; retailer private label brands producing IPM MP vegetables; and organisations responsible for controlling that food firm operations follow environmental standards (e.g., local, national, and European institutions or organizations) (variables $\mathrm{TR}_{1}-\mathrm{TR}_{4}$ ). Moreover, a set of respondent food shopping habits concerning the regular use of labelled information were investigated, focusing on: ingredients list, nutrition facts, geographical origin, shelf life, organic certifications, IPM certifications, and other sustainability logos or certifications (variables $\mathrm{HAB}_{1}-\mathrm{HAB}_{8}$ ). The questionnaire also included questions aimed at evaluating the level of concern regarding agricultural practices with regards to the use of chemicals and to the related potential environmental and health impacts $\left(\mathrm{CONC}_{1}-\mathrm{CONC}_{6}\right)$. 
Table 2 reports further details on the questions for each of the variable constructs.

\subsection{Data analysis}

4

Data were first analysed by means of descriptive statistics. Subsequently, a confirmatory factor analysis (CFA) was performed to evaluate the validity of the constructs of the conceptual model. Indeed, the single variables previously described were organised in factors as indicated in Table 2. 
Intention to purchase IPM MP vegetables IPM PM vegetables

MP vegetables with a low use of pesticides MP products with a reduced use of chemicals Attitude towards IPM MP vegetables

Pest control

Production costs compared to organic vegetables

Reduction in the use of pesticides

Reduction in the use of petrol

Reduction of air polluting emissions

Healthier conditions for farmers and the local community

Perceived availability of IPM MP vegetables

Supermarket availability

Price

Product placement

Price reductions

Institutional trust

Supply chain

Food processors

Retailers

Control institutions

Food shopping habits

Ingredients list

Nutrition facts

Geographical origin

Shelf life

Organic certification

IPM certification

Sustainability logo/certification

Agricultural practises concern

Environmental programs on chemical products in agriculture

Control activities on agricultural practices

Concern for the environmental impact

Concern for the health impact

Impact on water pollution

scale (1-5) Level of intention to purchase IPM minimally-processed vegetables (no intention=1, high intention=5)

scale (1-5) Level of intention to buy minimally-processed vegetables produced with a low use of pesticides (no intention=1, high intention=5)

scale (1-5) Level of intention to buy minimally-processed vegetables from producers using a reduced amount of chemicals' (no intention=1, high intention=5)

scale (1-5) Level of agreement with the following phrase: IPM minimally-processed vegetables imply pest control for specific pests (1= strongly disagree; $5=$ strongly agree)

scale (1-5) Level of agreement with the following phrase: IPM minimally-processed vegetables imply a reduction in production costs compared to organic vegetables (1= strongly disagree; $5=$ strongly agree)

scale (1-5) Level of agreement with the following phrase: IPM minimally-processed vegetables imply a reduction in the use of pesticides (1= strongly disagree; $5=$ strongly agree)

scale (1-5) Level of agreement with the following phrase: IPM minimally-processed vegetables imply a reduction in the use of petrol (1= strongly disagree; $5=$ strongly agree)

scale (1-5) Level of agreement with the following phrase: IPM minimally-processed vegetables imply a reduction in air polluting emissions (1= strongly disagree; $5=$ strongly agree)

scale (1-5) Level of agreement with the following phrase: IPM minimally-processed vegetables imply healthier conditions for farmers and the local community $(1=$ strongly disagree; $5=$ strongly agree)

scale (1-5) Level of agreement with the following phrase: 'The decision to buy IPM minimally-processed vegetables is related to the availability in supermarkets' (1= strongly disagree; $5=$ strongly agree)

scale (1-5) Level of agreement with the following phrase: 'IPM minimally-processed vegetables have competitive prices with respect to other minimally-processed vegetables' (1= strongly disagree; $5=$ strongly agree)

scale (1-5) Level of agreement with the following phrase: 'IPM minimally-processed vegetables have an easy-to-reach product placement' $1=$ strongly disagree; $5=$ strongly agree) scale (1-5) Level of agreement with the following phrase: 'IPM minimally-processed vegetables often have price reductions' ( $1=$ strongly disagree; $5=$ strongly agree)

scale (1-5) Level of trust in firms operating in the vegetables supply chain (1= very low trust; $5=$ very high trust $)$

scale (1-5) Level of trust in food processor brands producing IPM minimally-processed vegetables (1= very low trust; $5=$ very high trust)

scale (1-5) Level of trust in retailer private label brands producing IPM minimally-processed vegetables (1= very low trust; $5=$ very high trust)

scale (1-5) Level of trust in organisations controlling compliance with environmental standards (1= very low trust; $5=$ very high trust)

scale (1-5) Level of agreement with the following phrase: 'When shopping, I check the ingredients list on a regular basis' (1= strongly disagree; $5=$ strongly agree) scale (1-5) Level of agreement with the following phrase: 'When shopping, I check the nutrition facts on a regular basis' ( $1=$ strongly disagree; $5=$ strongly agree)

scale (1-5) Level of agreement with the following phrase: 'When shopping I check the geographical origin on a regular basis'( $1=$ strongly disagree; $5=$ strongly agree $)$

scale (1-5) Level of agreement with the following phrase: 'When shopping, I check the geographical origin on a regular basis' $(1=$ strongly disagree; $5=$ strongl $)$
scale (1-5) Level of agreement with the following phrase: 'When shopping, I check the shelf life on a regular basis' (1= strongly disagree; $5=$ strongly agree $)$

scale (1-5) Level of agreement with the following phrase: 'When shopping, I check the presence of the organic logo on a regular basis' (1= strongly disagree; $5=$ strongly agree)

scale (1-5) Level of agreement with the following phrase: 'When shopping, I check the presence of IPM logos on a regular basis' (1= strongly disagree; $5=$ strongly agree)

scale (1-5) Level of agreement with the following phrase: 'When shopping, I check the presence of sustainability logos or certifications on a regular basis' (1= strongly disagree; $5=$ strongly agree)

Level of agreement with the following phrase: 'Institutions should invest more money in environmental programs related to the use of chemical products in agriculture' (1= strongly disagree; $5=$ strongly agree)

scale (1-5) Level of agreement with the following phrase: 'Control activities on the environmental impact of agricultural practices are too scarce' (1= strongly disagree; $5=$ strongly agree)

Level of agreement with the following phrase: 'Environmentally-friendly agricultural practices imply a benefit for the environment' (1= strongly disagree; $5=$ strongly agree)

scale (1-5) Level of agreement with the following phrase: 'Environmentally-friendly agricultural practices imply a benefit for human health' (1= strongly disagree; $5=$ strongly agree) scale (1-5) Level of agreement with the following phrase: 'Agricultural practices have a strong impact on water pollution' ( $1=$ strongly disagree; $5=$ strongly agree) scale (1-5) Level of agreement with the following phrase: 'Agricultural practices have a negative impact on human health' ( $1=$ strongly disagree; $5=$ strongly agree)
INIENTION

$\mathrm{INT}_{1}$

$\mathrm{INT}_{2}$

$\mathrm{INT}_{3}$

$\mathrm{ATT}_{1}$

$\mathrm{ATT}_{2}$

$\mathrm{ATT}_{3}$

$\mathrm{ATT}_{4}$

ATT $_{6}$

PB CONTROI

$\mathrm{PBC}$

$\mathrm{PBC}_{2}$

$\mathrm{PBC}_{3}$

$\mathrm{PBC}_{4}$

TRUST

$\mathrm{TR}_{1}$

$\mathrm{TR}_{2}$

$\mathrm{TR}_{3}$

$\mathrm{TR}_{4}$

HABITS

$\mathrm{HAB}$

$\mathrm{HAB}_{2}$

$\mathrm{HAB}_{3}$

$\mathrm{HAB}_{4}$

$\mathrm{HAB}$

$\mathrm{HAB}_{6}$

$\mathrm{HAB}_{7}$

CONCERN

$\mathrm{CONC}_{1}$

$\mathrm{CONC}_{2}$

$\mathrm{CONC}_{3}$

$\mathrm{CONC}_{4}$

$\mathrm{CONC}_{5}$

$\mathrm{CONC}_{6}$

\section{Table 2: Variable description}


Results of the CFA are provided in Table 3. All constructs show acceptable internal consistency, with Cronbach's alpha values between 0.62-0.79 (Hair et al., 2010). Factor loadings were higher than the threshold of 0.3 proposed by Hair et al. (2010), except for variable $\mathrm{ATT}_{1}$ measuring the outcome evaluation regarding pest control. However, the authors indicate that such guideline value may decrease with sample size and factor dimensionality. Thus, given that pest control considerations are relevant for the research question, that such variable is included in a factor based on a high number of variables, and that the sample size is larger than 350, it was decided to keep $\mathrm{ATT}_{1}$ in the model. Moreover, the p-values of the Wald test suggest keeping such a variable. Indeed, all variables included in all factors of the CFA were significant at the 0.001 level $^{2}$. Table 4 reports the results of the correlation matrix. All correlations were well below 0.8 indicating that the factors were adequately separated (Brown, 2014; Sorbom, 1998).

\begin{tabular}{|c|c|c|c|c|c|c|c|}
\hline Variable & Alpha & Factor loading & $\begin{array}{l}\text { P-value } \\
\text {. }\end{array}$ & Variable & Alpha & Factor loading & $\begin{array}{l}\text {-value } \\
\text { - }\end{array}$ \\
\hline INTENTION & 0.78 & & & TRUST & 0.64 & & \\
\hline IPM MP vegetables & & 0.44 & 0.00 & Supply chain & & 0.58 & 0.00 \\
\hline MP vegetables with a low use of pesticides & & 0.96 & 0.00 & Food processors & & 0.50 & 0.00 \\
\hline \multirow{2}{*}{$\begin{array}{l}\text { MP vegetables from producers with a reduced } \\
\text { use of chemicals }\end{array}$} & & 0.90 & 0.00 & Retailers & & 0.54 & 0.00 \\
\hline & & & & Control institutions & & 0.53 & 0.00 \\
\hline ATIITUDE & 0.78 & & & & & & \\
\hline Pest control & & 0.21 & 0.00 & HABITS & 0.67 & & \\
\hline $\begin{array}{l}\text { Production costs compared to organic } \\
\text { vegetables }\end{array}$ & & 0.31 & 0.00 & Ingredients list & & 0.57 & 0.00 \\
\hline Reduction in the use of pesticides & & 0.75 & 0.00 & Nutrition facts & & 0.32 & 0.00 \\
\hline Reduction in the use of petrol & & 0.87 & 0.00 & Geographical origin & & 0.56 & 0.00 \\
\hline Reduction of air polluting emissions & & 0.88 & 0.00 & Shelf life & & 0.55 & 0.00 \\
\hline \multirow[t]{2}{*}{$\begin{array}{l}\text { Healthier conditions for farmers and the local } \\
\text { community }\end{array}$} & & 0.43 & 0.00 & Organic certification & & 0.45 & 0.00 \\
\hline & & & & IPM certification & & 0.44 & 0.00 \\
\hline PB CONTROL & 0.75 & & & Sustainability logos/certifications & & 0.32 & 0.00 \\
\hline Supermarket availability & & 0.73 & 0.00 & & & & \\
\hline Price & & 0.66 & 0.00 & CONCERN & 0.62 & & \\
\hline Product placement & & 0.53 & 0.00 & $\begin{array}{l}\text { Environmental programs on chemical } \\
\text { products in agriculture }\end{array}$ & & 0.48 & 0.00 \\
\hline \multirow[t]{5}{*}{ Price reductions } & & 0.71 & 0.00 & Control activities on agricultural practices & & 0.39 & 0.00 \\
\hline & & & & Concern for the environmental impact & & 0.37 & 0.00 \\
\hline & & & & Concern for the health impact & & 0.41 & 0.00 \\
\hline & & & & Impact on water pollution & & 0.47 & 0.00 \\
\hline & & & & Impact on human health & & 0.33 & 0.00 \\
\hline
\end{tabular}

Table 3 - Constructs and measurement items

${ }^{2}$ Given that, by default, the R package lavaan fixes the (unstandardized) factor loading of the first indicator to 1 , to evaluate the results of the Wald test for all indicators, several CFAs were performed, changing the order of the variables in the factors. The $p$-values reported in the table are the highest ones. 


\begin{tabular}{lcccccc} 
& \multicolumn{7}{c}{} & & & & \\
\cline { 2 - 7 } & INTENTION & ATTITUDE PB CONTROL & TRUST & HABITS & CONCERN \\
\hline INTENTION & 1.000 & & & & & \\
ATTITUDE & 0.029 & 1.000 & & & & \\
PB CONTROL & 0.474 & 0.056 & 1.000 & & & \\
TRUST & 0.285 & 0.179 & 0.312 & 1.000 & & \\
HABITS & -0.255 & 0.028 & -0.318 & 0.157 & 1.000 & \\
CONCERN & -0.305 & 0.420 & -0.045 & -0.145 & 0.593 & 1.000 \\
\hline
\end{tabular}

\section{Table 4 - Correlation matrix}

The data were analysed using structural equation modelling. This approach allows the evaluation of the relative importance of the different latent variables included in the conceptual framework in influencing intention to purchase IPM MP vegetables.

Two models with additional constructs were tested on the basis of the TPB and food economics literature (Figure 2). More specifically, model 1 tested the role of the fundamental TPB constructs, except for social norms, and model 2 included the constructs related to food shopping habits and agricultural practice concerns, and the role of trust as a background factor influencing attitude and concern. Indeed, literature has shown how trust influences consumer attitudes towards ‘production and processing methods' (Hobbs and Goddard, 2015; Lobb et al., 2007).

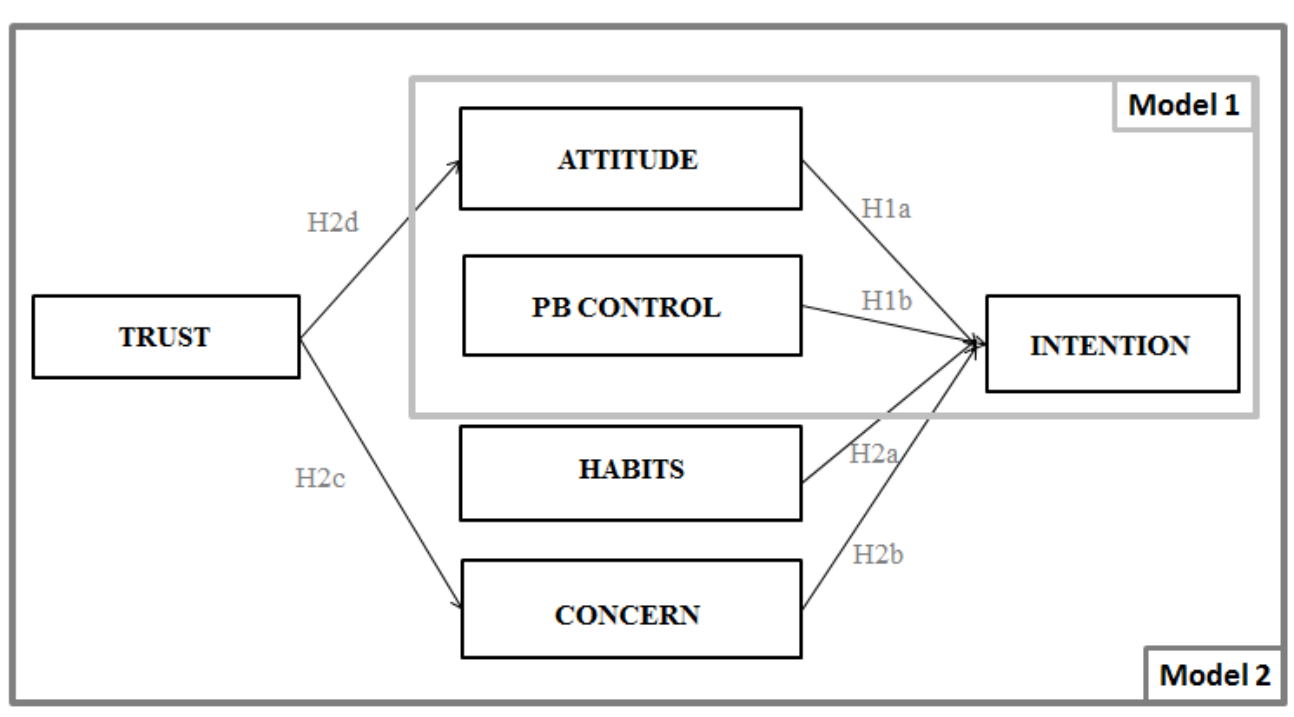

Figure 2: Structural equation models 
Furthermore, previous research findings have also highlighted the role of trust in influencing the acceptance of technological processes and food products by reducing risk perceptions (Hobbs and Goddard, 2015; Ross et al., 2014; Siegrist et al., 2008). Data analyses were carried out using the Lavaan package (Rosseel, 2012) of the R statistical software (R Core Team, 2013).

\section{Results}

\subsection{Descriptive statistics}

The main focus of the study is to analyse the role of trust in shaping the determinants of the intention to purchase IPM MP vegetables. Figure 3 reports the relative frequency of the answers to the four questions related to the respondents' level of trust $\left(\mathrm{TR}_{1}-\mathrm{TR}_{4}\right)$. The comparison of the results of the four questions highlights quite consistent results; indeed, the CFA confirmed their aggregation into one unique factor. However, some differences in distribution arose. In particular, what seems to emerge is that the lowest level of trust is towards institutions meant to control compliance of food firms with environmental standards. On the other hand, the levels of trust seem to be higher for food processing and retailer brands. This may be connected to the perceived importance attributed by firms to brand reputation and, thus, to a form of calculative trust (Hobbs and Goddard, 2015). 


\section{Figure 3 - Level of trust in the different food system actors}

We also analysed if trust levels vary with socio-demographic variables or the frequency of purchase of MP vegetables, whether or not they are IPM. Table 5 reports the sign and significance levels of such associations. What seems to emerge is that all else being equal, women are more confident with all actors in the food system compared to men. Moreover, education and income seem to have an effect, especially for trust in the supply chain and in the control institutions. Results do not find a significant effect of age. Finally, as would be expected, consumers that have higher levels of purchase of MP vegetables seem to have higher levels of trust compared to those who do not buy such products.

\begin{tabular}{|c|c|c|c|c|c|c|}
\hline \multirow[b]{2}{*}{ Trust variable } & \multicolumn{4}{|c|}{ Socio-demographic variables } & \multicolumn{2}{|c|}{ Frequency of purchase variables } \\
\hline & Gender & Age & Education & Income & MP veg. & IMP MP veg. \\
\hline Supply chain & $+* * *$ & n.s. & $+* * *$ & $+* * *$ & $+* * *$ & $+* * *$ \\
\hline Food processors & $+* *$ & n.s. & n.s. & n.s. & $+* * *$ & $+* * *$ \\
\hline Retailers & $+* * *$ & n.s. & $+* *$ & $+* *$ & $+* * *$ & $+* * *$ \\
\hline Control institutions & $+* * *$ & n.s. & $+* *$ & $+* * *$ & $+* * *$ & $+* * *$ \\
\hline
\end{tabular}

Notes : The table reports the sign of the relation and the significance level: $* * * \mathrm{p}<0.01 ; * * 0.01 \leq \mathrm{p}<0.05 ; * 0.05 \leq \mathrm{p}<$ 0.1 ; n.s. $\mathrm{p} \geq 0.1$

Table 5 - Associations between trust levels, socio-demographics, and purchase frequency variables 


\subsection{Structural equation model results}

The research hypotheses detailed in Section 2 were investigated by means of structural equation modelling. Table 6 reports the results of the two models explained in Section 3.3. More specifically, it presents the unstandardized estimate of each model variable, the standard errors, the Wald statistic, and its pvalue $^{3}$. Table 6 also details the model fit indices. Given the still open debate in the literature about how to evaluate model fit, a variety of indices of different classes are reported: absolute fit indices, incremental fit indices, and parsimony fit indices (Hu and Bentler, 1999; Kline, 2005). The results of the proposed model (model 2) indicate a reasonable fit. The values of some indices, like the adjusted goodness of fit index (AGFI), the comparative fit index (CFI), and the Tucker Lewis index (TLI), are slightly under the recommended level of 0.9 (Awang, 2012; Bentler and Bonett, 1980; Hooper et al., 2008). However, results for other fit indices are in line or below the guideline values. The $\chi 2 / \mathrm{df}$ is lower than the guideline values of 3 and 5 suggested by Kline (1998) and Schumacker and Lomax (2004), respectively. The value of the goodness of fit index (GFI) is just in line with the 0.9 threshold suggested by Hair et al. (2009) and Awang (2012). Other literature indicates that values higher than 0.80 suggest good fit (Forza and Filippini, 1998). The standardized root mean square residual (SRMR) of model 2 is 0.067 , lower than 0.08 that is considered an indicator of a good fit, especially in conjunction with low values of the root mean square error of approximation (RMSEA) (Hu and Bentler, 1999). The RMSEA of the proposed model and the related test of close fit indicates a 'good' fit (Hu and Bentler, 1999; MacCallum et al., 1996; Steiger, 2007). Given the discussion in the literature about using a set cut-off point estimate (Kenny et al., 2015), at least for

\footnotetext{
${ }^{3}$ The estimates of the standardised solution of model 2 are reported in Table 7.
} 
the RMSEA, the confidence interval for model 2 was calculated (0.046-0.054), suggesting that the degree of uncertainty about the estimate is limited.

\begin{tabular}{|c|c|c|c|c|c|c|}
\hline \multirow[t]{2}{*}{ Variable } & \multicolumn{3}{|c|}{ Model 1} & \multicolumn{2}{|c|}{$\begin{array}{c}\text { Model } 2 \\
\end{array}$} & \multirow[b]{2}{*}{ P-value } \\
\hline & Estimate & Z-value & P-value & Estimate & Z-value & \\
\hline \multicolumn{7}{|l|}{ Effect on intention $^{\#}$} \\
\hline ATTITUDE & $\begin{array}{l}-0.013 \\
(0.063)\end{array}$ & -0.207 & 0.836 & $\begin{array}{l}0.381^{* * *} \\
(1.43)\end{array}$ & 2.660 & 0.008 \\
\hline PB CONTROL & $\begin{array}{l}0.263^{* * *} \\
(0.38)\end{array}$ & 7.010 & 0.000 & $\begin{array}{l}0.285^{* * *} \\
(0.42)\end{array}$ & 6.783 & 0.000 \\
\hline HABITS & & & & $\begin{array}{l}0.129 * * \\
(0.62)\end{array}$ & 2.039 & 0.041 \\
\hline CONCERN & & & & $\begin{array}{l}-0.469^{* * *} \\
(1.21)\end{array}$ & -3.863 & 0.000 \\
\hline \multicolumn{7}{|l|}{ Effect on attitude } \\
\hline TRUST & & & & $\begin{array}{l}0.081^{* * *} \\
(0.30)\end{array}$ & 2.700 & 0.007 \\
\hline Effect on concern & & & & $-0.129 *$ & -1.809 & 0.071 \\
\hline TRUST & & & & $(0.071)$ & & \\
\hline \multicolumn{7}{|l|}{ Model fit indices } \\
\hline$\chi^{2} / \mathrm{df}$ & \multicolumn{3}{|c|}{5.46} & \multicolumn{3}{|c|}{2.38} \\
\hline GFI & \multicolumn{3}{|c|}{0.90} & \multicolumn{3}{|c|}{0.90} \\
\hline AGFI & \multicolumn{3}{|c|}{0.88} & \multicolumn{3}{|c|}{0.88} \\
\hline CFI & \multicolumn{3}{|c|}{0.88} & \multicolumn{3}{|c|}{0.88} \\
\hline TLI & \multicolumn{3}{|c|}{0.85} & \multicolumn{3}{|c|}{0.87} \\
\hline SRMR & \multicolumn{3}{|c|}{0.08} & \multicolumn{3}{|c|}{0.07} \\
\hline RMSEA & \multicolumn{3}{|c|}{0.09} & \multicolumn{3}{|c|}{0.05} \\
\hline P-value (RMSEA $<0.05$ ) & \multicolumn{3}{|c|}{0.00} & \multicolumn{3}{|c|}{0.48} \\
\hline RMSEA C.I. & \multicolumn{3}{|c|}{ 0.082-0.099 } & \multicolumn{3}{|c|}{$0.046-0.054$} \\
\hline
\end{tabular}

\# for a more clear representation of the relations tested by the model please refer to Figure 2.

Notes: Estimates refer to the unstandardised solution. IPM = integrated pest management; MP = minimally processed.

Significance levels: $* * * \mathrm{p}<0.01 ; * * 0.01 \leq \mathrm{p}<0.05 ; * 0.05 \leq \mathrm{p}<0.1$

$\chi^{2} / \mathrm{df}=$ Chi square /degrees of freedom; GFI= Goodness of Fit Index; AGFI=Adjusted Goodness of Fit Index; ; CFI

=Comparative Fit Index; TLI= Tucker Lewis Index, also known as Non-normed Fit Index; SRMR=Standardized

Root Mean Square Residual; RMSEA = root mean square error of approximation; C.I. = confidence interval.

Table 6 - Structural equation model results

Comparing the fit indices of the proposed extended model with those of the

basic TPB model, it emerges that model 2 shows a better fit with respect to

model 1. Some indices, show moderate changes, however, other indices indicate quite strong model fit improvements. More specifically, model 2 presents quite a large decrease in the RMSEA values compared to model 1: from 0.091 to 0.050. The same occurs for the RMSEA confidence interval. Moreover, the test of close fit, whose null hypothesis is that the RMSEA is less or equal to 0.05 (Kenny et al., 2015), also shows better results (p-value of 0.479 for model 2 compared to 
0.000 for model 1). Model 2 also shows an improved explanatory power in relation to the intention to purchase IPM MP vegetables $\left(\mathrm{R}^{2}=0.339\right.$ of model 2 compared to $\mathrm{R}^{2}=0.229$ of model 1 ), which also supports the inclusion of the additional variables in the model.

\subsection{Hypothesis testing and interpretation of the results}

Focusing on the hypotheses postulated in the conceptual framework, what emerges is that there is a positive very significant association of intention to purchase IPM MP vegetables with the attitude of consumers towards such products (H1a: ATTITUDE $\rightarrow$ INTENTION) and with perceived control variables (H1b: PB CONTROL $\rightarrow$ INTENTION), as is expected following Ajzen’s theory. Table 7 also highlights a very strong relation, especially with the control variable, which in the current model is related to the perceived availability at retail stores. Furthermore, model results confirm that food shopping habits related to label use may play a role in shaping purchase intention (H2a: HABITS $\rightarrow$ INTENTION), and that concern related to agricultural practices is also important and might deter very concerned consumers from buying IPM products that offer less warranty than organic products (H2b: CONCERN $\rightarrow$ INTENTION). The results also indicate that institutional trust in food supply chain-related actors (from food firms to control organisations) influences both the attitudes of consumers towards the IPM labelled products (H2d: TRUST $\rightarrow$ ATTITUDE) and the concern about the environmental and health-related impacts of agricultural practices (H2c: TRUST $\rightarrow$ CONCERN). More specifically, we find a strongly significant positive relation between trust and attitude, namely, the outcome evaluation of the purchase of IPM MP vegetables. This indicates that the more consumers trust supply chain-related actors, the more they would be willing to buy IPM MP 
vegetables. The relation with agricultural practices concern is instead negative (and mildly significant). This suggests that consumers who have more trust in the food system agents are less concerned about the environmental and health issues related to agricultural practices and show higher levels of intention to buy IPM products. This may indicate that building trust in IPM MP vegetable supply chain actors could be a way of promoting the purchase of such products.

\begin{tabular}{clccc}
\hline Hypothesis & \multicolumn{1}{c}{ Path } & Standardised estimate & p-value & Effect \\
\hline H1a & ATTITUDE $\rightarrow$ INTENTION & $0.193^{* * *}$ & 0.008 & supported \\
H1b & PB CONTROL $\rightarrow$ INTENTION & $0.497^{* * *}$ & 0.000 & supported \\
H2a & HABITS $\rightarrow$ INTENTION & $0.174^{* *}$ & 0.041 & supported \\
H2b & CONCERN $\rightarrow$ INTENTION & $-0.467^{* * *}$ & 0.000 & supported \\
H2c & TRUST $\rightarrow$ CONCERN & $-0.145^{*}$ & 0.071 & supported \\
H2d & TRUST $\rightarrow$ ATTITUDE & $0.179^{* * *}$ & 0.000 & supported \\
\hline
\end{tabular}

\section{Table 7 - Hypothesis testing}

\section{Discussion and implications}

\subsection{Results discussion}

The two models presented in the analysis confirm the efficacy of a TPB-based framework to explain consumer eco-friendly buying intention, particularly of the extended one. More specifically, model 1 highlights the strong role of perceived behavioural control in intention. Model 2 confirms results on the role of attitude and perceived behavioural control as in the TPB, and of food shopping habits and agricultural practices concern as in previous food economic literature (Cranfield and Magnusson, 2003; Govindasamy et al., 2001; Grankvist and Biel, 2001; Koenig-Lewis et al., 2014; Menozzi et al., 2015; Stranieri et al., 2017). Moreover, it also supports the hypotheses that trust can have a significant effect on consumer attitudes and concerns. Indeed, the results of model 2 confirm the validity of adding food-related variables to the standard TPB framework (model 2 vs. model 1). More specifically, the positive association between attitude and 
the intention to purchase IPM MP vegetables shows that consumer evaluations about the likely outcomes related to buying IPM MP are strong determinants of purchase intention. Moreover, the relevance of perceived behavioural control to the intention to buy IPM MP vegetables highlights how product accessibility is key to making sustainable choices, especially for convenience food shoppers, whose shopping is often characterised by time constraints in terms of product selection.

The role of commonly repeated actions and food habits while food shopping is also confirmed in the results of the study. The analysis highlights a significant impact of consumer search for product information on eco-friendly behaviour. This result corroborates previous literature on the effectiveness of informationbased food policy instruments in creating consumer awareness and focusing consumers on sustainable food consumption (Reisch et al., 2013; Verain et al., 2015).

In contrast to results on organic produce, concern for the environmental and health impacts of agriculture shows a negative association with purchasing intention. This result suggests that this type of product may not be attractive to the very concerned consumer who prefers organic food, but could instead be targeted at the share of the population who might not be committed enough to pay the premium price needed to purchase organic products but might still demand more eco-friendly attributes in their food. Such products may, indeed, be a means of engaging with environmentally friendly food choice consumers who are not already active on such issues or consumers who do not reveal environmentally conscious behaviour.

The model also indicates that institutional trust can affect consumer risk perception, in line with existing literature (Lobb et al., 2007; Siegrist et al., 
2007; Tonsor et al., 2009; Wee et al., 2014). Indeed, what seems to emerge is that consumers who trust the supply chain-related agents - including IPM food processors and retailer brands and control institutions - are less concerned with the possible negative impacts on the environment and human health of agricultural practices, and, thus, show a positive intention to purchase these products that provide intermediate levels of consumer warranty on such aspects. The results also highlight a strong positive association between trust in the different supply chain-related actors and the intention to purchase IPM MP vegetables. Indeed, the more consumers have trust, the more they have a positive attitude towards such products, and, thus, the more they are, again, willing to purchase them. Indeed, results confirm that trust can be included as a background factor for the intention to buy eco-friendly convenience products. This is in accordance with Hobbs and Goddard (2015), who discuss the role of trust as a cognitive shortcut when deciding among food products, especially in the absence of 'knowledge, experience or familiarity with firms'. Indeed, following the insights of this study, low levels of institutional trust may hinder the purchase of environmentally sustainable products that could promote environmentally friendly behaviour by food firms, and thus environmentally related societal benefits (e.g., impact reduction).

\subsection{Implications}

The present research contributes both from a theoretical and practical point of view point. It provides an integrated framework to better explain and interpret consumer eco-friendly behaviour in relation to convenience food products. Moreover, the present analysis confirms theoretically the importance of trust as a determinant in consumer behavioural models. From a managerial and policy perspective, the role of consumer attitudes in shaping consumer intentions to buy 
IPM MP vegetables highlights the importance of information campaigns explaining to consumers how IPM products are produced and how they differ, on the one hand, from conventional products, and, on the other, from organic ones. The large amount of separate voluntary private initiatives regarding IPM practices does not allow for quick and easy understanding and recognition of IPM products. As a consequence, it may induce confusion in the final consumer and require too high information cost for many convenience food consumers, who aim at saving time and effort. Information and education campaigns adopting different means at different levels of engagement may increase the understanding and the salience of the specific characteristics and motivations to purchase IPM products.

The importance of product perceived availability suggests that making ecofriendly convenience products more accessible cost-wise - by providing discounts - or time and convenience-wise - by allowing a larger distribution among retailers and making them more easily recognisable - could be important options for increasing their diffusion. Indeed, literature has highlighted how high price and limited availability are important reasons that hinder purchase of organic products (Aschemann-Witzel and Niebuhr Aagaard, 2014). Thus, promoting accessibility to IPM convenience food could be a way of engaging with sustainable behaviour consumers who are not committed enough or able to buy organic food but who would be willing to act more sustainably.

In this study, the significance of habits referring to information search on labels highlights, once again, the potential benefits of a common and easily recognisable logo or claim for IPM products to be noticed (and possibly used to select products) by consumers who are not as accustomed to check labels thoroughly. However, it should be considered that eco-friendly labelling 
schemes are expected to nudge, in particular, those consumers who are already engaged in sustainable food consumption (Steiner et al., 2017; Banterle et al., 2018).

Institutional trust can instead be considered as a strategic determinant to be reinforced in order to promote sustainable food consumption to consumers who are not particularly involved in eco-friendly behaviour. The present analysis underlines the importance of identifying and implementing policies aimed at improving trust in the food supply chain-related agents. Literature indicates that trust levels may be influenced both positively and negatively (Wales et al., 2006). Confidence in supply chain-related actors can be dramatically reduced by food scares and by fraudulent labelling. In the case of eco-friendly production processes, trust is not so much a matter of food safety but rather of believing that the indicated characteristics are actually present. Indeed, the adoption of IPM procedures in production is a credence attribute that cannot be verified directly by the consumer, but is just matter of faith. For what concerns MP vegetables or convenience food in general, there are issues related to trust in the processing technology. Strategies and policies that build consumer trust are not readily identifiable. Indeed, in addition to consumers not having complete information, trust is a complex phenomenon that does not depend only on rational judgments about risks, but involves both cognitive and emotional aspects (Tonkin et al., 2016a, 2016b). Thus, literature is increasingly highlighting how improving consumer information and knowledge is not a very effective quick-fix to increase consumer trust (Eden et al., 2008). Nevertheless, such measures may build positive attitudes towards products and affect concerns towards agricultural practices, which, in turn, affect purchase intention. Indeed, more information and knowledge may engage consumers on the topic of the use of 
chemicals in agriculture, either by responding to concerned consumers, or, possibly, increasing concerns of previously unconcerned consumers. In any case, this increases consumer consciousness of the impacts of everyday choices, which is a positive result.

Returning to the discussion on how to influence trust levels, labelling has been identified by the literature as a way to affect 'consumer perceptions of trustworthiness' and to reinforce trust in the food system, even if interpretation of the labelled information may not necessarily remain strictly within the correct regulatory definition (Tonkin et al., 2016a, 2016b).

Transparency, communication, and engagement may play a role in increasing consumer confidence, especially in institutions (Hobbs and Goddard, 2015). This is particularly relevant given that the results of the present study suggest that particular attention should be devoted to building trust for public institutions, which seems to be - at least in the sample of the study - lower than trust in private firms and their brands. Such measures can increase both consumer information - working on the cognitive side of trust - and consumer perceptions and 'feelings' about the agents. Consumers are, indeed, increasingly getting used to (and valuing) having a more proactive role and being directly engaged in public and private decisions in different sectors (Markandya and Ricci, 2012). Reorganisation and ability to adapt regulation to the continuously evolving food market risks may also be important to build trust in authorities (Wales et al., 2006).

Trust may also be considered a social phenomenon (Hobbs and Goddard, 2015; Tonkin et al., 2016b). Indeed, trust levels may be influenced by social interactions. Word-of-mouth (WOM) has been known to have a strong influence on product diffusion (Bass, 1969), thus, policies aimed at increasing trust could 
be targeted at groups, taking advantage of diffusion processes therein. Moreover, current information and communication technologies (IC\&T) technologies have for some years now allowed consumers to search and share information and opinions not only among their small circle of personal contacts but also with geographically distant consumers via electronic WOM, possibly amplifying the effects of policies promoting trust. These aggregation possibilities are particularly relevant for building/reducing trust in organisations and affecting firm reputation (Dellarocas, 2003; King et al., 2014).

\section{Conclusion, limitations, and future research directions}

The results of the present analysis highlight the role of trust in shaping consumer eco-friendly behaviour and it sheds light on the way trust influences behavioural variables in the case of food products characterized by contradicting attributes in relation to consumer perceptions, namely, convenience and eco-friendly attributes.

When analysing the insights from this study, however, a few limitations should be taken into account. The sample of respondents includes consumers living in a metropolitan area; thus, the results are not representative of the Italian population but rather of consumers living in a large European city. Furthermore, results are based on stated preferences. This follows from the TPB and from the need to collect data otherwise unavailable, like intentions, attitudes, perceptions, and control issues. Nevertheless, biases in responses may arise due to the nature of the data. To try to reduce the hypothetical nature of the questions, respondents were interviewed in front of supermarkets. Interviewing respondents 'while voluntarily thinking about food shopping' should increase their ability to recall their decisional processes and choices. Moreover, the current analysis stops at 
the evaluation of the purchasing intention rather than at the behaviour itself. Nevertheless, the TPB theoretical framework and previous research shows how intentions and behaviour are strongly related, even if intentions do not always turn into actual behaviour (Sheeran and Webb, 2016). Even in the presence of the above limitations, the current research still contributes to the literature as it is among the few studies on the relation between consumer trust and consumer purchasing intention for convenience food with environmentally friendly attributes.

Future work may want to focus also on other types of consumers living in more rural areas to get a wider picture of the issue. Research should also test the robustness of the results on other types of convenience food with environmentally sustainable attributes. Moreover, it would be useful to analyse further the topic looking at different types of trust: trust in the information given by firms via labelling and trust related to technology adoption. Future research effort should also be devoted to study the determinants of trust and how trust is diffused via social interaction and other diffusion channels to be able to evaluate the impacts of different policies.

\section{References}

Abouab, N., Gomez, P., 2015. Human contact imagined during the production process increases food naturalness perceptions. Appetite 91, 273-277. https://doi.org/10.1016/j.appet.2015.04.002

Aertsens, J., Verbeke, W., Mondelaers, K., Huylenbroeck, G.V., 2009. Personal determinants of organic food consumption: a review. British Food Journal 111, 1140-1167. https://doi.org/10.1108/00070700910992961 
Agovino, M., Crociata, A., Quaglione, D., Sacco, P., Sarra, A., 2017. Good Taste Tastes Good. Cultural Capital as a Determinant of Organic Food Purchase by Italian Consumers: Evidence and Policy Implications. Ecological Economics 141, 6675. https://doi.org/10.1016/j.ecolecon.2017.05.029

Ajzen, I., 1991. The theory of planned behavior. Organizational Behavior and Human Decision Processes, Theories of Cognitive Self-Regulation 50, 179-211. https://doi.org/10.1016/0749-5978(91)90020-T

Ajzen, I., 1985. From Intentions to Actions: A Theory of Planned Behavior, in: Kuhl, J., Beckmann, J. (Eds.), Action Control. Springer Berlin Heidelberg, Berlin, Heidelberg, pp. 11-39.

Ajzen, I., Fishbein, M., 1980. Understanding attitudes and predicting social behaviour. Armitage, C.J., Conner, M., 2001. Efficacy of the Theory of Planned Behaviour: A meta-analytic review. British Journal of Social Psychology 40, 471-499. https://doi.org/10.1348/014466601164939

Arvola, A., Vassallo, M., Dean, M., Lampila, P., Saba, A., Lähteenmäki, L., Shepherd, R., 2008. Predicting intentions to purchase organic food: The role of affective and moral attitudes in the Theory of Planned Behaviour. Appetite 50, 443-454. https://doi.org/10.1016/j.appet.2007.09.010

Aschemann-Witzel, J., Niebuhr Aagaard, E.M., 2014. Elaborating on the attitudebehaviour gap regarding organic products: young Danish consumers and in-store food choice. International Journal of Consumer Studies 38, 550-558. https://doi.org/10.1111/ijcs.12115

Asioli, D., Aschemann-Witzel, J., Caputo, V., Vecchio, R., Annunziata, A., Næs, T., Varela, P., 2017. Making sense of the “clean label” trends: A review of consumer food choice behavior and discussion of industry implications. FOOD RES.INT. 99, 58-71. https://doi.org/10.1016/j.foodres.2017.07.022 
Awang, Z., 2012. Structural equation modeling using AMOS graphic. Penerbit Universiti Teknologi MARA.

Bamberg, S., 2003. How does environmental concern influence specific environmentally related behaviors? A new answer to an old question. Journal of Environmental Psychology 23, 21-32. https://doi.org/10.1016/S02724944(02)00078-6

Banterle, A., Ricci, E.C., Cavaliere, A., 2018. Environmental sustainability and the food system. In: Bremmers, H., Purnhagen, K. (Eds.), Regulating Food Safety Law in the EU - a Management and Economics Perspective. Springer, forthcoming.

Banterle, A., Stranieri, S., 2013. Sustainability standards and the reorganization of private label supply chains: A transaction cost perspective. Sustainability 5(12), $5272-5288$.

Baselice, A., Colantuoni, F., Lass, D.A., Nardone, G., Stasi, A., 2017. Trends in EU consumers’ attitude towards fresh-cut fruit and vegetables. Food Quality and Preference 59, 87-96. https://doi.org/10.1016/j.foodqual.2017.01.008

Bass, F.M., 1969. A New Product Growth for Model Consumer Durables. Management Science 15, 215-227. https://doi.org/10.1287/mnsc.15.5.215

Bentler, P.M., Bonett, D.G., 1980. Significance tests and goodness of fit in the analysis of covariance structures. Psychological bulletin 88, 588.

Blanchard, C.M., Fisher, J., Sparling, P.B., Shanks, T.H., Nehl, E., Rhodes, R.E., Courneya, K.S., Baker, F., 2009. Understanding Adherence to 5 Servings of Fruits and Vegetables per Day: A Theory of Planned Behavior Perspective. Journal of Nutrition Education and Behavior 41, 3-10. https://doi.org/10.1016/j.jneb.2007.12.006 
Bond, C.A., Thilmany, D.D., Bond, J.K., 2008. What to Choose? The Value of Label Claims to Fresh Produce Consumers. Journal of Agricultural and Resource Economics 33, 402-427.

Botonaki, A., Mattas, K., 2010. Revealing the values behind convenience food consumption. Appetite 55, 629-638.

Bougherara, D., Combris, P., 2009. Eco-labelled food products: what are consumers paying for? European review of agricultural economics 36, 321-341.

Brown, T.A., 2014. Confirmatory Factor Analysis for Applied Research, Second Edition. Guilford Publications.

Bruhn, C.M., 2007. Enhancing consumer acceptance of new processing technologies. Innovative Food Science \& Emerging Technologies 8, 555-558.

Brunner, T.A., van der Horst, K., Siegrist, M., 2010. Convenience food products. Drivers for consumption. Appetite 55, 498-506. https://doi.org/10.1016/j.appet.2010.08.017

Çabuk, S., Tanrikulu, C., Gelibolu, L., 2014. Understanding organic food consumption: attitude as a mediator. International journal of consumer studies 38, 337-345. Chalamon, I., Nabec, L., 2016. Why Do We Read On-Pack Nutrition Information so Differently? A Typology of Reading Heuristics Based on Food Consumption Goals. J Consum Aff 50, 403-429. https://doi.org/10.1111/joca.12093

Chen, M.-F., 2016. Extending the theory of planned behavior model to explain people’s energy savings and carbon reduction behavioral intentions to mitigate climate change in Taiwan-moral obligation matters. Journal of Cleaner Production 112, 1746-1753.

Cranfield, J.A.L., Magnusson, E., 2003. Canadian Consumer’s Willingness-To-Pay For Pesticide Free Food Products: An Ordered Probit Analysis. International Food and Agribusiness Management Review 6, 13-30. 
de Bruijn, G.-J., 2010. Understanding college students’ fruit consumption. Integrating habit strength in the theory of planned behaviour. Appetite 54, 16-22. https://doi.org/10.1016/j.appet.2009.08.007

De Groot, J., Steg, L., 2007. General Beliefs and the Theory of Planned Behavior: The Role of Environmental Concerns in the TPB. Journal of Applied Social Psychology 37, 1817-1836. https://doi.org/10.1111/j.1559-1816.2007.00239.x

De Leeuw, A., Valois, P., Ajzen, I., Schmidt, P., 2015. Using the theory of planned behavior to identify key beliefs underlying pro-environmental behavior in highschool students: Implications for educational interventions. Journal of Environmental Psychology 42, 128-138.

DeBono, K.G., Snyder, M., 1995. Acting on one’s attitudes: The role of a history of choosing situations. Personality and Social Psychology Bulletin 21, 629-636.

Del Giudice, T., Stranieri, S., Caracciolo, F., Ricci, E.C., Cembalo, L., Banterle, A., Cicia, G., 2018. Corporate Social Responsibility certifications influence consumer preferences and seafood market price. Journal of Cleaner Production 178, 526-533.

Dellarocas, C., 2003. The Digitization of Word of Mouth: Promise and Challenges of Online Feedback Mechanisms. Management Science 49, 1407-1424. https://doi.org/10.1287/mnsc.49.10.1407.17308

Diamantopoulos, A., Sarstedt, M., Fuchs, C., Wilczynski, P., Kaiser, S., 2012. Guidelines for choosing between multi-item and single-item scales for construct measurement: a predictive validity perspective. J. of the Acad. Mark. Sci. 40, 434-449. https://doi.org/10.1007/s11747-011-0300-3 
Diem, M.N.H., Rutsaert, P., Van Loo, E.J., Verbeke, W., 2017. Consumers’ familiarity with and attitudes towards food quality certifications for rice and vegetables in Vietnam. Food Control.

Dixon, C.J., Leach, B., 1977. Sampling methods for geographical research. Geo Abstracts Ltd.

Eden, S., Bear, C., Walker, G., 2008. Understanding and (dis)trusting food assurance schemes: Consumer confidence and the “knowledge fix.” Journal of Rural Studies 24, 1-14. https://doi.org/10.1016/j.jrurstud.2007.06.001

Evans, G., de Challemaison, B., Cox, D.N., 2010. Consumers’ ratings of the natural and unnatural qualities of foods. Appetite 54, 557-563.

Falguera, V., Aliguer, N., Falguera, M., 2012. An integrated approach to current trends in food consumption: Moving toward functional and organic products? Food Control 26, 274-281. https://doi.org/10.1016/j.foodcont.2012.01.051

Forza, C., Filippini, R., 1998. TQM impact on quality conformance and customer satisfaction: A causal model. International Journal of Production Economics 55, $1-20$.

Geeroms, N., Verbeke, W., Van Kenhove, P., 2008. Consumers’ health-related motive orientations and ready meal consumption behaviour. Appetite 51, 704-712. https://doi.org/10.1016/j.appet.2008.06.011

Godin, G., Conner, M., Sheeran, P., 2005. Bridging the intention-behaviour gap: The role of moral norm. British journal of social psychology 44, 497-512.

Godin, G., Kok, G., 1996. The theory of planned behavior: a review of its applications to health-related behaviors. American journal of health promotion 11, 87-98.

Goetzke, B., Nitzko, S., Spiller, A., 2014. Consumption of organic and functional food. A matter of well-being and health? Appetite 77, 96-105. 
Govindasamy, R., Italia, J., Adelaja, A., others, 2001. Predicting willingness-to-pay a premium for integrated pest management produce: a logistic approach. Agricultural and Resource Economics Review 30, 151-159.

Grankvist, G., Biel, A., 2001. The importance of beliefs and purchase criteria in the choice of eco-labeled food products. Journal of Environmental Psychology 21, 405-410.

Grebitus, C., Steiner, B., Veeman, M., 2015. The roles of human values and generalized trust on stated preferences when food is labeled with environmental footprints: Insights from Germany. Food Policy 52, 84-91.

Grunert, K.G., Hieke, S., Wills, J., 2014. Sustainability labels on food products: Consumer motivation, understanding and use. Food Policy 44, 177-189. https://doi.org/10.1016/j.foodpol.2013.12.001

Guillaumie, L., Godin, G., Vézina-Im, L.-A., 2010. Psychosocial determinants of fruit and vegetable intake in adult population: a systematic review. International Journal of Behavioral Nutrition and Physical Activity 7, 12.

Hair, J.F., Jr, Black, W.C., Babin, B.J., Anderson, R.E., 2010. Multivariate Data Analysis, 7 edizione. ed. Prentice Hall College Div, Upper Saddle River, NJ. Harland, P., Staats, H., Wilke, H.A., 1999. Explaining proenvironmental intention and behavior by personal norms and the theory of planned behavior1. Journal of applied social psychology 29, 2505-2528.

Hemmerling, S., Hemmerling, S., Canavari, M., Canavari, M., Spiller, A., Spiller, A., 2016. Preference for naturalness of European organic consumers: First evidence of an attitude-liking gap. British Food Journal 118, 2287-2307.

Hobbs, J.E., Goddard, E., 2015. Consumers and trust. Food Policy 52, 71-74. https://doi.org/10.1016/j.foodpol.2014.10.017 
Honkanen, P., Olsen, S.O., Verplanken, B., 2005. Intention to consume seafood-the importance of habit. Appetite 45, 161-168.

Honkanen, P., Verplanken, B., Olsen, S.O., 2006. Ethical values and motives driving organic food choice. Journal of Consumer Behaviour 5, 420-430.

Hooper, D., Coughlan, J., Mullen, M., 2008. Structural equation modelling: Guidelines for determining model fit. Electronic Journal of Business Research Methods 6, 53-60.

Hu, L., Bentler, P.M., 1999. Cutoff criteria for fit indexes in covariance structure analysis: Conventional criteria versus new alternatives. Structural Equation Modeling: A Multidisciplinary Journal 6, 1-55. https://doi.org/10.1080/10705519909540118

Jackson, P., Viehoff, V., 2016. Reframing convenience food. Appetite 98, 1-11.

Johe, M.H., Bhullar, N., 2016. To buy or not to buy: The roles of self-identity, attitudes, perceived behavioral control and norms in organic consumerism. Ecological Economics 128, 99-105. https://doi.org/10.1016/j.ecolecon.2016.02.019

Kaiser, F.G., Hübner, G., Bogner, F.X., 2005. Contrasting the Theory of Planned Behavior With the Value-Belief-Norm Model in Explaining Conservation Behavior1. Journal of applied social psychology 35, 2150-2170.

Kenny, D.A., Kaniskan, B., McCoach, D.B., 2015. The Performance of RMSEA in Models With Small Degrees of Freedom. Sociological Methods \& Research 44, 486-507. https://doi.org/10.1177/0049124114543236

King, R.A., Racherla, P., Bush, V.D., 2014. What We Know and Don’t Know About Online Word-of-Mouth: A Review and Synthesis of the Literature. Journal of Interactive Marketing 28, 167-183. https://doi.org/10.1016/j.intmar.2014.02.001

Kline, R.B., 2005. Methodology in the social sciences. Principles and practice of structural equation modeling. New York: Guilford Press. 
Kline, R.B., 1998. Principles and practice of structural equation modeling. Guilford publications.

Koenig-Lewis, N., Palmer, A., Dermody, J., Urbye, A., 2014. Consumers’ evaluations of ecological packaging-Rational and emotional approaches. Journal of Environmental Psychology 37, 94-105.

Lee, H.-J., Yun, Z.-S., 2015. Consumers’ perceptions of organic food attributes and cognitive and affective attitudes as determinants of their purchase intentions toward organic food. Food quality and preference 39, 259-267.

Lobb, A.E., Mazzocchi, M., Traill, W.B., 2007. Modelling risk perception and trust in food safety information within the theory of planned behaviour. Food Quality and Preference 18, 384-395. https://doi.org/10.1016/j.foodqual.2006.04.004

Lyly, M., Roininen, K., Honkapää, K., Poutanen, K., Lähteenmäki, L., 2007. Factors influencing consumers' willingness to use beverages and ready-to-eat frozen soups containing oat $\beta$-glucan in Finland, France and Sweden. Food Quality and Preference 18, 242-255.

MacCallum, R.C., Browne, M.W., Sugawara, H.M., 1996. Power analysis and determination of sample size for covariance structure modeling. Psychological methods 1,130 .

Magkos, F., Arvaniti, F., Zampelas, A., 2006. Organic food: buying more safety or just peace of mind? A critical review of the literature. Critical reviews in food science and nutrition 46, 23-56.

Markandya, A., Ricci, E. C., 2012. Green Taxes on Aviation: The Case of Italy. The Proposal of the Green Taxation Matrix. In Environmental Taxes and Fiscal Reform (pp. 168-206). Palgrave Macmillan, London. 
McComas, K.A., Besley, J.C., Steinhardt, J., 2014. Factors influencing US consumer support for genetic modification to prevent crop disease. Appetite 78, 8-14.

Menozzi, D., Halawany-Darson, R., Mora, C., Giraud, G., 2015. Motives towards traceable food choice: A comparison between French and Italian consumers. Food Control 49, 40-48.

Menozzi, D., Mora, C., 2012. Fruit consumption determinants among young adults in Italy: A case study. LWT-Food Science and Technology 49, 298-304.

Menozzi, D., Sogari, G., Mora, C., 2017a. Understanding and modelling vegetables consumption among young adults. LWT - Food Science and Technology 85, 327-333. https://doi.org/10.1016/j.lwt.2017.02.002

Menozzi, D., Sogari, G., Veneziani, M., Simoni, E., Mora, C., 2017b. Eating novel foods: An application of the Theory of Planned Behaviour to predict the consumption of an insect-based product. Food Quality and Preference 59, 27-34. https://doi.org/10.1016/j.foodqual.2017.02.001

Meredith, S., Willer, H., 2016. Organic in Europe. Prospects and Developments 2016. IFOAM EU Group, Brussels, Belgium.

Michaelidou, N., Hassan, L.M., 2008. The push and pull towards organic: clarifying the roles of health consciousness, food safety concern and ethical identity. International Journal of Consumer Studies 32, 163-170.

Mondelaers, K., Verbeke, W., Van Huylenbroeck, G., 2009. Importance of health and environment as quality traits in the buying decision of organic products. British Food Journal 111, 1120-1139.

Nassivera, F., Sillani, S., 2017. Consumer Behavior Toward Eco-Labeled Minimally Processed Fruit Product. Journal of International Food \& Agribusiness Marketing 29, 29-45. https://doi.org/10.1080/08974438.2016.1241734 
Nuttavuthisit, K., Thøgersen, J., 2017. The importance of consumer trust for the emergence of a market for green products: The case of organic food. Journal of Business Ethics 140, 323-337.

Olsen, N.V., 2012. The convenience consumer’s dilemma. British Food Journal 114, $1613-1625$.

Pearson, D., Henryks, J., Jones, H., 2011. Organic food: What we know (and do not know) about consumers. Renewable Agriculture and Food Systems 26, 171-177.

Pino, G., Peluso, A.M., Guido, G., 2012. Determinants of regular and occasional consumers' intentions to buy organic food. Journal of Consumer Affairs 46, 157-169.

Prati, G., Pietrantoni, L., Zani, B., 2012. The prediction of intention to consume genetically modified food: Test of an integrated psychosocial model. Food Quality and Preference 25, 163-170.

Pugliese, P., Zanasi, C., Atallah, O., Cosimo, R., 2013. Investigating the interaction between organic and local foods in the Mediterranean: The Lebanese organic consumer’s perspective. Food Policy 39, 1-12.

R Core Team, 2013. R: A language and environment for statistical computing. $\mathrm{R}$ Foundation for Statistical Computing, Vienna, Austria.

Ragaert, P., Verbeke, W., Devlieghere, F., Debevere, J., 2004. Consumer perception and choice of minimally processed vegetables and packaged fruits. Food Quality and Preference 15, 259-270.

Reisch, L., Eberle, U., Lorek, S., 2013. Sustainable food consumption: an overview of contemporary issues and policies. Sustainability: Science, Practice, \& Policy 9. Rollin, F., Kennedy, J., Wills, J., 2011. Consumers and new food technologies. Trends in Food Science \& Technology 22, 99-111. 
Román, S., Sánchez-Siles, L.M., Siegrist, M., 2017. The importance of food naturalness for consumers: Results of a systematic review. Trends in Food Science \& Technology 67, 44-57. https://doi.org/10.1016/j.tifs.2017.06.010

Ross, V.L., Fielding, K.S., Louis, W.R., 2014. Social trust, risk perceptions and public acceptance of recycled water: Testing a social-psychological model. Journal of environmental management 137, 61-68.

Rosseel, Y., 2012. lavaan: an R package for structural equation modeling and more Version 0.4-9 (BETA). Journal of Statistical Software 48.

Saba, A., Di Natale, R., 1998. A study on the mediating role of intention in the impact of habit and attitude on meat consumption. Food Quality and Preference 10, 6977.

Saba, A., Messina, F., 2003. Attitudes towards organic foods and risk/benefit perception associated with pesticides. Food quality and preference 14, 637-645.

Scarpa, R., Del Giudice, T., 2004. Market segmentation via mixed logit: extra-virgin olive oil in urban Italy. Journal of Agricultural and Food Industrial Organization 2, 1-18.

Schösler, H., De Boer, J., Boersema, J.J., 2013. The organic food philosophy: A qualitative exploration of the practices, values, and beliefs of Dutch organic consumers within a cultural-historical frame. Journal of Agricultural and Environmental Ethics 26, 439-460.

Schulte-Mecklenbeck, M., Sohn, M., de Bellis, E., Martin, N., Hertwig, R., 2013. A lack of appetite for information and computation. Simple heuristics in food choice. Appetite 71, 242-251. https://doi.org/10.1016/j.appet.2013.08.008

Schumacker, R.E., Lomax, R.G., 2004. A beginner's guide to structural equation modeling. Psychology Press. 
Shafie, F.A., Rennie, D., 2012. Consumer perceptions towards organic food. ProcediaSocial and Behavioral Sciences 49, 360-367.

Sheeran, P., Norman, P., Orbell, S., 1999. Evidence that intentions based on attitudes better predict behaviour than intentions based on subjective norms. European journal of social psychology 29, 403-406.

Sheeran, P., Webb, T.L., 2016. The Intention-Behavior Gap. Social and Personality Psychology Compass 10, 503-518. https://doi.org/10.1111/spc3.12265

Siegrist, M., Cousin, M.-E., Kastenholz, H., Wiek, A., 2007. Public acceptance of nanotechnology foods and food packaging: The influence of affect and trust. Appetite 49, 459-466.

Siegrist, M., Stampfli, N., Kastenholz, H., 2008. Consumers’ willingness to buy functional foods. The influence of carrier, benefit and trust. Appetite 51, 526529. https://doi.org/10.1016/j.appet.2008.04.003

Sillani, S., Nassivera, F., 2015. Consumer behavior in choice of minimally processed vegetables and implications for marketing strategies. Trends in Food Science \& Technology 46, 339-345.

Smith, J.R., Terry, D.J., Manstead, A.S., Louis, W.R., Kotterman, D., Wolfs, J., 2008. The attitude-behavior relationship in consumer conduct: The role of norms, past behavior, and self-identity. The Journal of social psychology 148, 311-334.

Soler, F., Gil, J.M., Sanchez, M., 2002. Consumers’ acceptability of organic food in Spain: results from an experimental auction market. British Food Journal 104, 670-687.

Sorbom, D., 1998. LISREL 8: Structural Equation Modeling with the SIMPLIS Command Language. Scientific Software, Hillsdale, NJ.

Spaargaren, G., Mol, A.P.J., 2008. Greening global consumption: Redefining politics and authority. Global Environmental Change, Globalisation and Environmental 
Governance: Is Another World Possible? 18, 350-359. https://doi.org/10.1016/j.gloenvcha.2008.04.010

Sparks, P., Shepherd, R., Wieringa, N., Zimmermanns, N., 1995. Perceived behavioural control, unrealistic optimism and dietary change: an exploratory study. Appetite 24, 243-255.

Steg, L., Vlek, C., 2009. Encouraging pro-environmental behaviour: An integrative review and research agenda. Journal of Environmental Psychology, Environmental Psychology on the Move 29, 309-317. https://doi.org/10.1016/j.jenvp.2008.10.004

Steiger, J.H., 2007. Understanding the limitations of global fit assessment in structural equation modeling. Personality and Individual differences 42, 893-898.

Steiner, B.E., Peschel, A.O., Grebitus, C., 2017. Multi-Product Category Choices Labeled for Ecological Footprints: Exploring Psychographics and Evolved Psychological Biases for Characterizing Latent Consumer Classes. Ecological Economics 140, 251-264.

Storstad, O., Bjørkhaug, H., 2003. Foundations of production and consumption of organic food in Norway: common attitudes among farmers and consumers? Agriculture and Human Values 20, 151-163.

Stranieri, S., Baldi, L., 2017. Shelf Life Date Extension of Fresh-Cut Salad: A Consumer Perspective. Journal of Food Products Marketing 23 (8), 939-954.

Stranieri, S., Ricci, E.C., Banterle, A., 2017. Convenience food with environmentallysustainable attributes: A consumer perspective. Appetite 116, 11-20. https://doi.org/10.1016/j.appet.2017.04.015

Suki, N.M., 2016. Consumer environmental concern and green product purchase in Malaysia: structural effects of consumption values. Journal of Cleaner 
Production, Absolute Reductions in Material Throughput, Energy Use and Emissions 132, 204-214. https://doi.org/10.1016/j.jclepro.2015.09.087

Tarkiainen, A., Sundqvist, S., 2005. Subjective norms, attitudes and intentions of Finnish consumers in buying organic food. British food journal 107, 808-822.

Tonkin, E., Meyer, S.B., Coveney, J., Webb, T., Wilson, A.M., 2016a. The process of making trust related judgements through interaction with food labelling. Food Policy 63, 1-11. https://doi.org/10.1016/j.foodpol.2016.06.007

Tonkin, E., Webb, T., Coveney, J., Meyer, S.B., Wilson, A.M., 2016b. Consumer trust in the Australian food system - The everyday erosive impact of food labelling. Appetite, Consumer psychology and portion size: making smaller better 103, 118-127. https://doi.org/10.1016/j.appet.2016.04.004

Tonsor, G.T., Schroeder, T.C., Pennings, J.M., 2009. Factors impacting food safety risk perceptions. Journal of Agricultural Economics 60, 625-644.

Trafimow, D., Finlay, K.A., 1996. The importance of subjective norms for a minority of people: Between subjects and within-subjects analyses. Personality and social psychology bulletin 22, 820-828.

Turaga, R.M.R., Howarth, R.B., Borsuk, M.E., 2010. Pro-environmental behavior. Annals of the New York Academy of Sciences 1185, 211-224.

Van der Putte, B., 1991. 20 years of the theory of reasoned action of Fishbein and Ajzen. A meta-analysis. Unpublished manuscript, University of Amsterdam. Van Loo, E.J., Caputo, V., Nayga, R.M., Verbeke, W., 2014. Consumers’ valuation of sustainability labels on meat. Food Policy 49, 137-150.

van Rijswick, C., 2011. The EU Fresh-cut Fruits and Vegetables Market, Rabobank International.

van Rijswick, C., 2010. EU Fresh-cut Fruits and Vegetables Market Update. Rabobank. 
Verain, M.C.D., Dagevos, H., Antonides, G., 2015. Sustainable food consumption. Product choice or curtailment? Appetite 91, 375-384. https://doi.org/10.1016/j.appet.2015.04.055

Vermeir, I., Verbeke, W., 2008. Sustainable food consumption among young adults in Belgium: Theory of planned behaviour and the role of confidence and values. Ecological Economics 64, 542-553. https://doi.org/10.1016/j.ecolecon.2007.03.007

Vermeir, I., Verbeke, W., 2006. Sustainable Food Consumption: Exploring the Consumer “Attitude - Behavioral Intention” Gap. J Agric Environ Ethics 19, 169-194. https://doi.org/10.1007/s10806-005-5485-3

Volland, B., 2017. The role of risk and trust attitudes in explaining residential energy demand: Evidence from the United Kingdom. Ecological Economics 132, 14-30. https://doi.org/10.1016/j.ecolecon.2016.10.002

Wales, C., Harvey, M., Warde, A., 2006. Recuperating from BSE: The shifting UK institutional basis for trust in food. Appetite 47, 187-195.

Wee, C.S., Ariff, M.S.B.M., Zakuan, N., Tajudin, M.N.M., Ismail, K., Ishak, N., 2014. Consumers Perception, Purchase Intention and Actual Purchase Behavior of Organic Food Products - ProQuest. Review of Integrative Business and Economics Research 3, 378-397.

Yadav, R., Pathak, G.S., 2017. Determinants of Consumers’ Green Purchase Behavior in a Developing Nation: Applying and Extending the Theory of Planned Behavior. Ecological Economics 134, 114-122.

Yadav, R., Pathak, G.S., 2016. Intention to purchase organic food among young consumers: Evidences from a developing nation. Appetite 96, 122-128.

Zhou, Y., Thøgersen, J., Ruan, Y., Huang, G., 2013. The moderating role of human values in planned behavior: the case of Chinese consumers â 
buy organic food. Journal of Consumer Marketing 30, 335-344.

2 https://doi.org/10.1108/JCM-02-2013-0482

3 